\title{
Tiempos de demora para la publicación de artículos en una revista científica peruana
}

\author{
Delay time for the publication of articles in a Peruvian scientific journal
}

\author{
Alfredo Enrique Oyola-García ${ }^{1, a}$, Willer David Chanduvi-Puicón ${ }^{2, b}$, \\ Melisa Pamela Quispe-llanzo $0^{1, c}$ \\ ${ }^{1}$ Natural and Social Sciences Research. \\ Escuela del Instituto Nacional de Estadistica e Informática. \\ ${ }^{a}$ Médico; ${ }^{b}$ Bachiller en Estadistica; ${ }^{\circ}$ Licenciada en Enfermería.
}

\section{An Fac med. 2015;76(4):467-8 / http://dx.doi.org/10.15381/anales.v76i4.11422}

\section{SR. EDITOR:}

Las revistas científicas tienen una importante función en la difusión de los resultados obtenidos en investigaciones, así como en la crítica de los conocimientos ya establecidos ${ }^{(1)}$. Su calidad depende -entre otros aspectos- de la rapidez del proceso de selección y de publicación (proceso editorial) de los artículos ${ }^{(2)}$.

Revisamos 264 artículos publicados electrónicamente en la Revista Peruana de Medicina Experimental y Salud Pública del Instituto Nacional de Salud del Perú, durante los años 2012 y

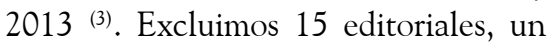
artículo de simposio y un artículo original -que no tenían fechas de recepción y aceptación- y dos cartas al editor con incongruencia en las fechas consignadas -fecha de aceptación previa a la fecha de recepción-. Finalmente, se evaluaron 245 artículos clasificados en dos grupos: a) artículos generales (artículos de revisión, cartas al editor y artículos de las secciones: especial, simposio, galería fotográfica e historia) y b) artículos de investigación (artículo original, original breve y reporte de casos). Los artículos de investigación se clasificaron en estudios observacionales (reportes de caso[s], descriptivos y analíticos) y estudios experimentales. El tiempo de demora se calculó en días, según lo consignado en cada artículo publicado en la revista, haciendo uso de la función "RESTAR" del programa Microsoft Excel@ 2010 para Windows
Tabla 1. Estadísticos descriptivos de los tiempos de demora en días.

\begin{tabular}{ccccccc}
\multirow{2}{*}{ Tiempo de demora } & \multirow{N}{*}{} & \multicolumn{5}{c}{ Estadísticos descriptivos (días) } \\
\cline { 3 - 7 } & & Mínimo & Máximo & Media & Desv. Est. & Mediana \\
Recepción - Aceptación & 245 & 0 & 461 & 64,60 & 63,11 & 45,00 \\
Aceptación - Publicación & 245 & 3 & 228 & 61,71 & 35,20 & 53,00 \\
Recepción - Publicación & 245 & 5 & 516 & 126,31 & 75,44 & 107,00 \\
\hline
\end{tabular}

XP®, y se clasificó como: a) recepciónaceptación; b) aceptación-publicación; y c) recepción-publicación. Se consideró como fecha de publicación el último día calendario del mes al que correspondía el número de la revista.
La mayoría de los artículos demoran en ser aceptados un mes y medio a dos meses, pero podría extenderse hasta más de un año. Demorarán -en promedio- un mes menos si son artículos generales, pero un mes y medio más si son
Tabla 2. Estadísticos descriptivos de los tiempos de demora en dias según tipo de artículo o estudio.

\begin{tabular}{|c|c|c|c|c|c|c|c|}
\hline $\begin{array}{l}\text { Tiempo de demora / } \\
\text { Tipo de artículo }\end{array}$ & $\mathrm{N}$ & Mínimo & Máximo & Media & $\begin{array}{l}\text { Desv. } \\
\text { Est. }\end{array}$ & Mediana & Sig. \\
\hline \multicolumn{8}{|l|}{ Recepción - aceptación } \\
\hline Artículos generales & 145 & 0 & 461 & 37,35 & 51,87 & 23,00 & \multirow{2}{*}{0,000} \\
\hline Artículos de investigación & 100 & 7 & 271 & 104,12 & 56,90 & 92,00 & \\
\hline Estudios experimentales & 8 & 67 & 175 & 102,38 & 38,46 & 92,00 & \multirow{2}{*}{0,888} \\
\hline Estudios observacionales & 91 & 7 & 246 & 102,44 & 55,98 & 91,00 & \\
\hline \multicolumn{8}{|l|}{ Aceptación - publicación } \\
\hline Artículos generales & 145 & 3 & 228 & 59,63 & 36,15 & 53,00 & \multirow{2}{*}{0,112} \\
\hline Artículos de investigación & 100 & 3 & 165 & 64,72 & 33,72 & 55,00 & \\
\hline Estudios experimentales & 8 & 38 & 118 & 64,63 & 24,54 & 60,50 & \multirow{2}{*}{0,807} \\
\hline Estudios observacionales & 91 & 3 & 165 & 64,46 & 34,60 & 55,00 & \\
\hline \multicolumn{8}{|l|}{ Recepción - publicación } \\
\hline Artículos generales & 145 & 5 & 516 & 96,98 & 65,19 & 83,00 & \multirow{2}{*}{0,000} \\
\hline Artículos de investigación & 100 & 40 & 360 & 168,84 & 68,99 & 157,50 & \\
\hline Estudios experimentales & 8 & 110 & 293 & 167,00 & 59,80 & 149,00 & \multirow{2}{*}{0,928} \\
\hline Estudios observacionales & 91 & 40 & 296 & 166,9 & 67,43 & 158,00 & \\
\hline
\end{tabular}


artículos de investigación. Los estudios experimentales y observacionales son aceptados en tiempos promedios similares (aproximadamente tres meses y medio), pero estos últimos presentan un tiempo máximo mayor, inclusive hasta más de un año de espera. Algunos artículos son aceptados el mismo día de su recepción -la mitad de ellos eran cartas al editor-.

En estos tiempos de demora influye el compromiso de respetar los plazos del proceso editorial que tiene el revisor del artículo o el investigador en el levantamiento de las observaciones que se le plantean. Además, el cumplimiento estricto de las normas de publicación de la revista por parte de los investigadores ayuda a que los revisores puedan dedi- car su tiempo a revisar los aspectos más técnicos y científicos del manuscrito ${ }^{(4)}$.

\section{REFERENCIAS BIBLIOGRÁFICAS}

1. Szklo M, Nieto FJ. El papel de las revistas en salud pública. Rev San Hig Púb. 1993 (citado 05 ene 2015); 67:331-334. Disponible en: http://www. msssi.gob.es/gl/biblioPublic/publicaciones/recursos_propios/resp/revista_cdrom/VOL67/67_5_331. pdf

2. Miyahira J. Criterios de calidad de las revistas científicas. Rev Med Hered (internet). 2008 (citado 11 nov 14); 19 (1):1-4. Disponible en: http://www. scielo.org.pe/pdf/rmh/v19n1/v19n1ed1.pdf

3. Revista Peruana de Medicina Experimental y Salud Pública (internet). Instituto Nacional de Salud del Perú. (citado 05 ene 2015). Disponible en: http://www.rpmesp.ins.gob.pe/portalweb/ Otros_numeros.htm

4. Navarro L, Sánchez JM, Cortina J, JiménezEguizábal L. En manos de la buena voluntad de los colegas...En nuestras manos. Ecosistemas (internet). 2010 (citado 11 nov 14); 19(1):1-7.
Disponible en: http://www.revistaecosistemas.net/ index.php/ecosistemas/article/view/397

Carta al Editor recibida el 5 de mayo de 2015.

Este artículo no ha sido publicado ni remitido previa o paralelamente a otra revista científica, congreso u otro que derive en publicación del mismo.

Los datos utilizados para esta investigación son de acceso libre y están disponibles en internet, por 10 que no se requirió de la autorización de la institución.

La investigación fue autofinanciada y no recibió apoyo de alguna institución u organización.

Correspondencia:

Alfredo Enrique Oyola-García

Dirección: Conjunto Habitacional "Abraham Valdelomar" C-201, Ica

Teléfono: 956124996

Correo electrónico: aoyola@redmed-ica.com 